\title{
Thermal and Mechanical Properties of Vinyl Ester Hybrid Composites with Carbon Black and Glass Reinforcement
}

\author{
Geetanjali S. Guggari, ${ }^{1}$ S. Shivakumar, ${ }^{1}$ G. A. Manjunath, ${ }^{1}$ R. Nikhil, ${ }^{1}$ Alagar Karthick (D), ${ }^{2}$ \\ Abhilash Edacherian, ${ }^{3}$ C. Ahamed Saleel $\mathbb{D}^{3},{ }^{3}$ Asif Afzal, ${ }^{4,5}$ S. Prasath ${ }^{\mathbb{D}},{ }^{6}$ and B. Saleh ${ }^{7}$ \\ ${ }^{1}$ Department of Mechanical Engineering, KLS Gogte Institute of Technology, Belagavi 590008, Karnataka, India \\ ${ }^{2}$ Department of Electrical and Electronics Engineering, KPR Institute of Engineering and Technology, Coimbatore 641407, \\ Tamilnadu, India \\ ${ }^{3}$ Department of Mechanical Engineering, College of Engineering King Khalid University, Asir Abha 61421, Saudi Arabia \\ ${ }^{4}$ Department of Mechanical Engineering, P. A. College of Engineering (Affiliated to Visvesvaraya Technological University, \\ Belagavi), Mangalore 574153, India \\ ${ }^{5}$ Department of Mechanical Engineering, School of Technology, Glocal University, Delhi-Yamunotri Marg, SH-57, Mirzapur Pole, \\ Saharanpur, Uttar Pradesh 247121, India \\ ${ }^{6}$ Department of Mechanical Engineering, College of Engineering and Technology Mizan Tepi University Tepi Campus, \\ Teppi 121, Ethiopia \\ ${ }^{7}$ Mechanical Engineering Department, College of Engineering Taif University, P.O. Box 11099, Taif 21944, Saudi Arabia
}

Correspondence should be addressed to S. Prasath; prasath@mtu.edu.et

Received 14 July 2021; Accepted 2 September 2021; Published 21 September 2021

Academic Editor: Mohanavel V

Copyright $\odot 2021$ Geetanjali S. Guggari et al. This is an open access article distributed under the Creative Commons Attribution License, which permits unrestricted use, distribution, and reproduction in any medium, provided the original work is properly cited.

\begin{abstract}
The objective of the work is to investigate both thermal and mechanical properties of vinyl ester/glass composites incorporated with different percentages of carbon black reinforcements through experimental approaches. Analysis of glass transition temperature, thermogravimetric analysis (TGA), degradation temperature, hardness, flexural strength, etc. is performed using differential scanning calorimeter, X-ray diffraction, tensile machine, and flexural machine, respectively. The scanning electron microscope was used for surface fracture studies. The degradation temperature reduces initially with the percentage of carbon black and then increases. Glass transition temperature increases with the percentage of carbon black while above $500^{\circ} \mathrm{C}$ temperature, the weight percentage of composite drops. The results also reveal that $4 \%$ of carbon with vinyl ester improved the tensile strength by $30 \%$, hardness by $35 \%$, flexural strength by $45 \%$, flexural modulus by $66 \%$, and interlaminate shear strength by $44 \%$ when compared with the other percentage of carbon black.
\end{abstract}

\section{Introduction}

Recent studies reported improved performance of carbon black dispersed polymer nanocomposites by exfoliating carbon black in polymeric resin. Several researchers [1-4] studied the effect of processing techniques on the dispersion of polymeric resin and reported that a high shear force mixing enabled better exfoliation, higher basal spacings, greater surface area, and increased interaction of carbon black platelets in polymeric resin. Dispersion of carbon black in thermoset resins such as epoxy and vinyl ester resin $[5,6]$ also showed better exfoliation and improved mechanical properties in case of high shear mixing and low volume fraction of carbon black.

Microhardness of polymer nanocomposites indicates surface hardness and is enhanced by nanofiller addition due to the addition of harder phase in soft polymer matrix. Ho et al. [7] reported increase in microhardness by $17.34 \%$ with the addition of $8 \mathrm{wt} . \%$ of garamite carbon black in epoxy. Lam and Lau [8] studied 0 to 4 wt.\% of SiO2/epoxy using a 
mechanical stirrer and ultrasonicator and reported that microhardness increased by $16.96 \%$ with the addition of 4 wt.\% $\mathrm{SiO} 2$ to epoxy. Review of the open literature on the study of microhardness of carbon black/polymer revealed that microhardness of carbon black/polymer depends on the amount of carbon black added to the polymer.

Sundaram et al. [9] reported that adding 5 wt.\% UTS can increase UTS by $50 \%$, increase yield strength by $7.24 \mathrm{~N} / \mathrm{mm}^{2}$, and increase Poisson's ratio by $50 \%$. \% ceramic is higher than polyester/glass. Add $10 \%$ by weight. For the same sample, \% carbon black increased the elongation by $3.9 \%$. Haque et al. [10] reported that for every addition of $1 \mathrm{wt} . \%$, the interlaminar shear strength, flexural strength, and fracture toughness increased by $8 \%$, $17 \%$, and $23 \%$, respectively. Kornmann et al. [11] reported that after adding carbon black to epoxy/glass, the flexural strength increased by $27 \%$ and Young's modulus increased by $6 \%$. The increase in flexural modulus is attributed to the presence of layered silicate, which increases the flexural strength of the fiber and improves the interface properties between the matrix and the fiber. There are many studies on mechanical properties [12], but there are few or no studies on the thermodynamic properties of nanohydride composite materials. The purpose of this project is to study the effect of carbon black on the thermal and mechanical properties of vinyl ester hybrid composites Nikhil et al. [13] discussed delaminations which occur due to improper binding, nonuniform distribution of resin, presence of foreign particles, absorption of moisture, nonuniform compaction during pressing of laminate, and curing of resin along the layers.

\section{Experimental Studies}

Polymer nanocomposite specimens were prepared using carbon blacks as a reinforcement which significantly influence the dispersion efficiency and mechanical and barrier properties of the nanocomposites. Carbon black was dispersed in vinyl ester using ultrasonication followed by twin screw extrusion, and carbon black/vinyl ester specimens were prepared. Carbon black/vinyl ester (VE)/glass (GF) nanocomposite laminates were prepared using carbon black-dispersed vinyl ester and $360 \mathrm{gsm}$ woven glass fiber mat by wet hand layup technique and the fabrication technique. Specimens were prepared by moulding the mixture of $\mathrm{CB}$ and vinyl ester in a sun mica mould of $100 \times 100 \times 1 \mathrm{~mm}^{3}$. X-ray diffraction $(\mathrm{XRD})$ and differential scanning calorimetry (DSC) were used to characterize the phases present in specimens and glass transition temperature ( $\mathrm{Tg}$ ) of $\mathrm{CB} /$ vinyl ester specimens. Vickers microhardness is used to measure the microhardness of $\mathrm{CB} /$ vinyl ester nanocomposites. A universal testing machine (UTM) is used to determine ultimate tensile strength (UTS), Young's modulus, flexural strength, flexural modulus, and interlaminar shear strength (ILSS). Scanning electron microscopy (SEM) was used to characterize surface geomorphology of $\mathrm{CB} /$ vinyl ester specimens as well as tensile fractured surface of $\mathrm{CB} /$ vinyl ester/glass composites. The specimens were characterized by XRD, DSC, SEM, and TEM according to the ASTM procedure.

\section{Experimental Results}

3.1. X-Ray Deflection of Carbon Black/Vinyl Ester. Figure 1 shows XRD of vinyl ester, carbon black, and 2 to 5 wt.\% carbon black/vinyl ester composites, the amorphous structure without any sharp peak as a general characterisation of noncrystalline polymeric material. XRD of carbon blacks in characteristic peaks at 7.70, 2.870, and 3.320 of $2 \theta$ indicated basal spacing of $11.38 \AA$, $31.5 \AA$, and $26.53 \AA$ for carbon black.

\subsection{Differential Scanning Calorimetry of Carbon Black/Vinyl} Ester. Figure 2 presents the sway of carbon black on the glass conversion temperature ( $\mathrm{Tg}$ ) of vinyl ester obtained from DSC. The highest increase in $\mathrm{Tg}$ was achieved with the addition of $5 \mathrm{wt} . \% \mathrm{CB}$. Increase in Tg of vinyl ester was achieved for carbon black due to complete exfoliation of carbon black in vinyl ester as indicated by XRD and TEM studies. Amount of carbon black and type of carbon black influenced $\mathrm{Tg}$ of vinyl ester.

3.3. Thermogravimetric Analysis. Figure 3(a) shows TGA pattern for 0 to $5 \mathrm{wt} . \% \mathrm{CB} /$ vinyl ester, and degradation temperature is presented in Figure 3(b). The weight reduction is due to the volatile nature of the molecules which release the functional ions. Degradation temperature for neat vinyl ester was $349^{\circ} \mathrm{C}$, and the same was lower for 2 and $4 \mathrm{wt} . \%$ of CB and slightly higher for 3 and $5 \mathrm{wt}$. CB addition to vinyl ester. Degradation of vinyl ester and $\mathrm{CB} /$ vinyl ester occurred in a single step which indicates that only resin phases volatilized during this period.

The degradation rate for $\mathrm{CB} /$ vinyl ester was comparatively lower than that of neat vinyl ester. Such a behavior can be explained by the presence of stacked carbon layers in vinyl ester which can act as thermal barrier to the vinyl ester system and decelerated the degradation process. Carbon is used as a thermal insulation layer to enhance the overall thermal stability of the system and help form carbon after complete thermal degradation. The mass loss of the completely decomposed $\mathrm{CB} /$ vinyl ester is $4 \mathrm{wt}$.\% less than pure vinyl ester. By adding $\mathrm{CB}$ to vinyl ester, a marginal improvement in thermal stability and clay yield can be observed.

3.4. Microhardness of $C B /$ Vinyl Ester. Figure 4 shows microhardness of 0 to $5 \mathrm{wt}$. $\mathrm{CB} /$ vinyl ester composite specimens. The setup for microhardness testing used is microindentation hardness testing machine. Microhardness increased with the addition of $\mathrm{CB}$, and the improvement was $20.96 \%, 36.81 \%$, and $21.95 \%$ with the addition of $\mathrm{CB}$. Microhardness improved due to the addition of harder CB in soft vinyl ester matrix. Amount and type of $\mathrm{CB}$ influenced the microhardness of vinyl ester.

While testing materials such as metals, the microhardness linearly correlates with the tensile strength. 


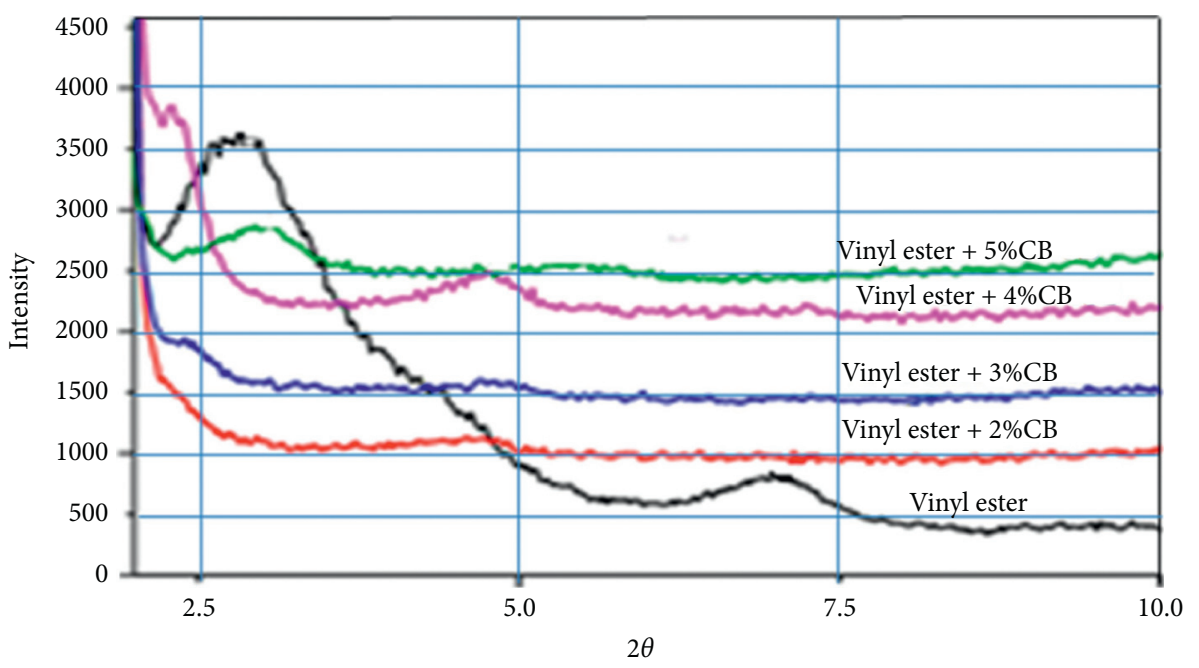

FIgURE 1: XRD pattern for vinyl ester and its composites.

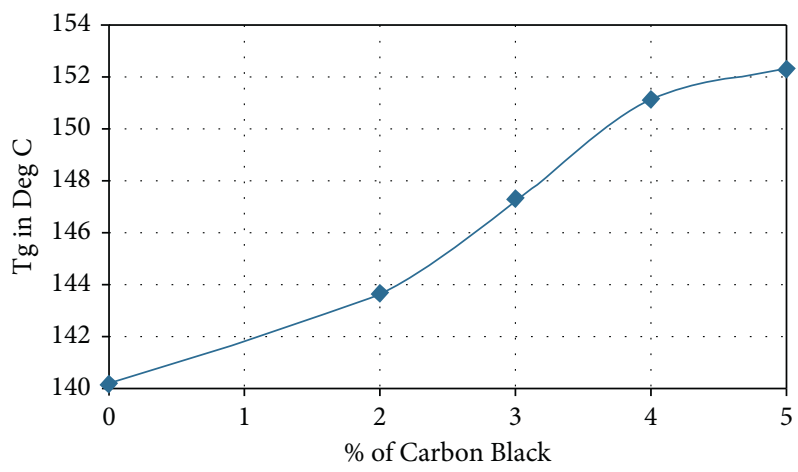

FIgURE 2: Effect of carbon black on Tg of the vinyl ester composites.

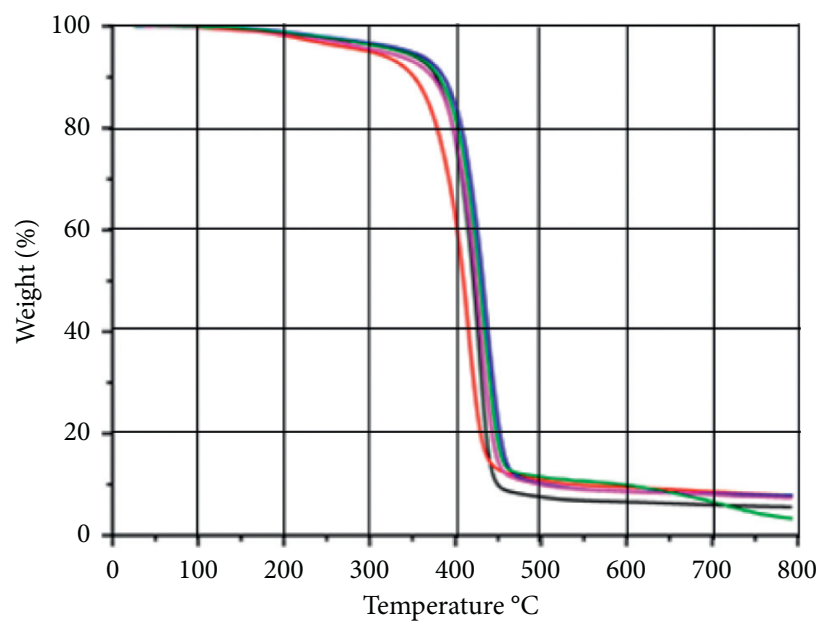

(a)

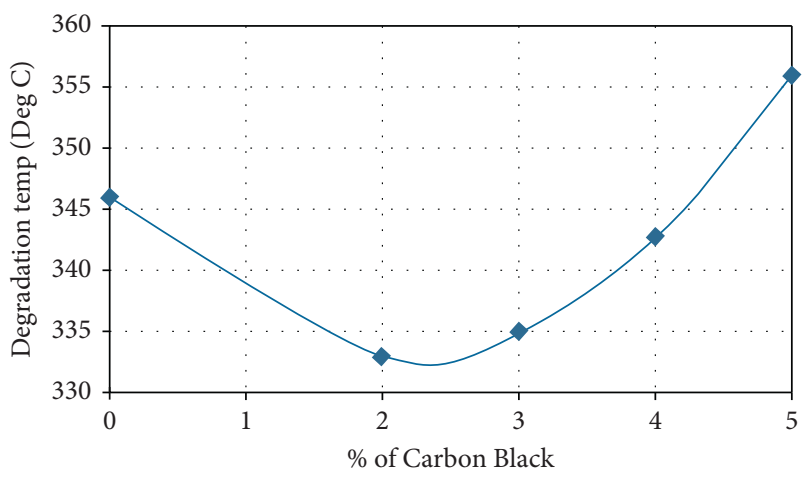

(b)

Figure 3: (a) Effect of carbon black on thermal stability (\% of degradation) of the vinyl ester composites. (b) Effect of carbon black on degradation temperature of the vinyl ester composites.

3.5. Ultimate Tensile Strength and Young's Modulus of Carbon Black/Vinyl Ester/Glass Composites. Figures 5(a) and 5(b) show ultimate tensile strength (UTS) and Young's modulus of various percentages of carbon black reinforced glass reinforced vinyl ester nanocomposites. UTS and Young's modulus increased with the addition of carbon black. Improvements in UTS are $31.35 \%, 34.64 \%$, and $20.62 \%$ and in Young's modulus $21.61 \%, 32.12 \%$, and $16.55 \%$ with the 


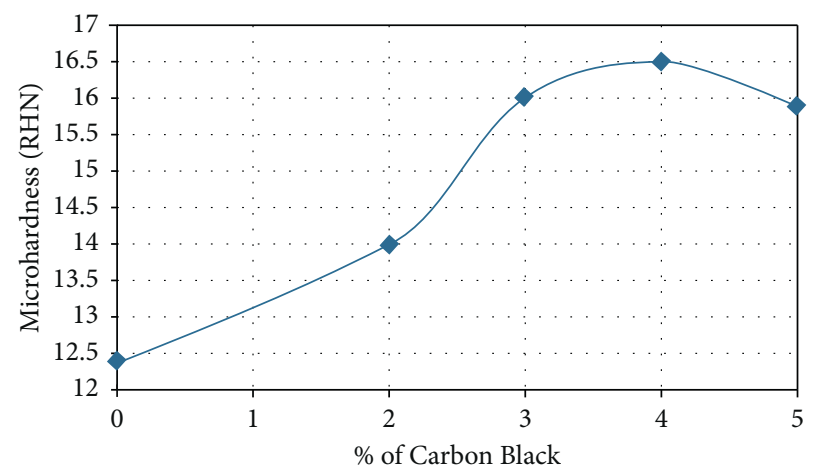

Figure 4: Effect of carbon black on microhardness of the vinyl ester composites.

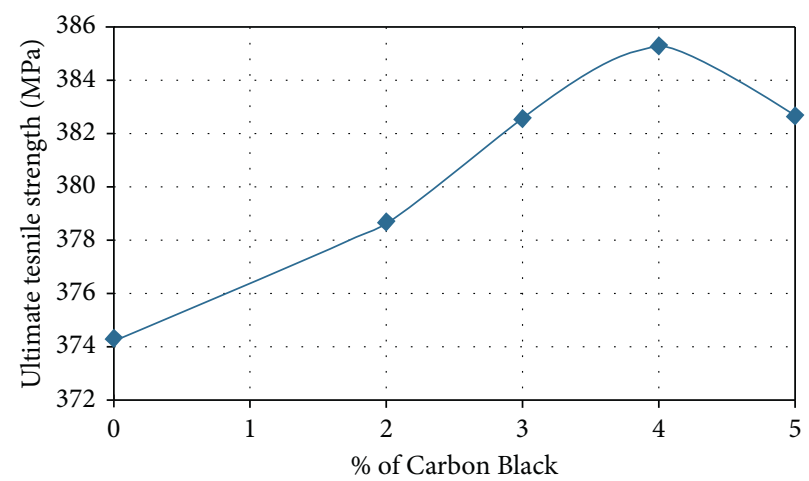

(a)

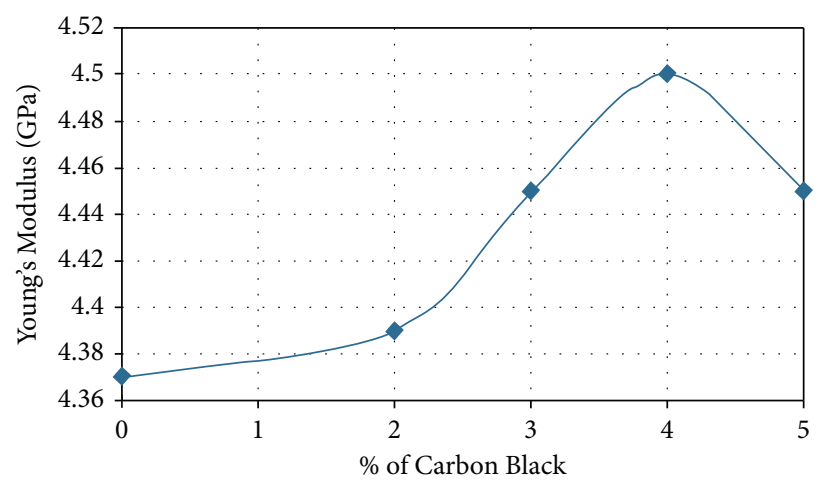

(b)

FIGURE 5: (a) Effect of carbon black on ultimate tensile strength of the vinyl ester composites. (b) Effect of carbon black on Young's modulus of the vinyl ester composites.

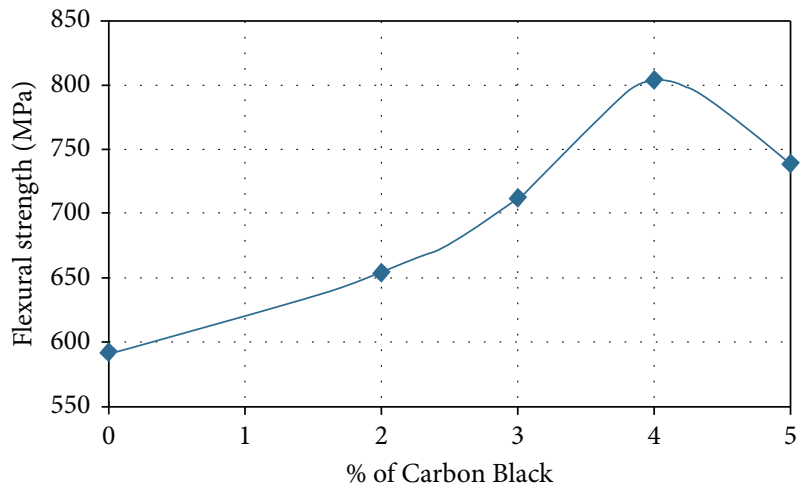

(a)

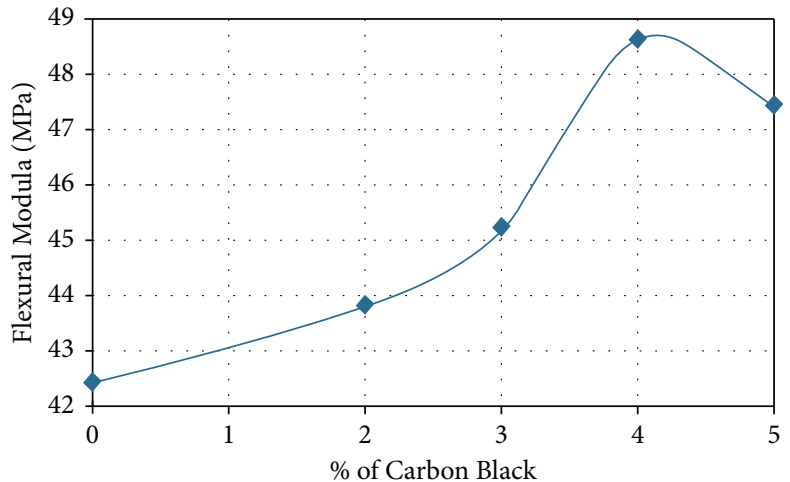

(b)

FIGURE 6: (a) Effect of carbon black on flexural strength of the vinyl ester composites. (b) Effect of carbon black on flexural modulus of the vinyl ester composites.

addition of 4 wt.\% each of carbon black reinforced vinyl ester/ glass composites. Both UTS and Young's modulus show highest for 4 wt.\% addition to vinyl ester/glass composites.

\subsection{Flexural Strength and Flexural Modulus of Carbon Black/} Vinyl Ester/Glass. Figures 6(a) and 6(b) show flexural strength and flexural modulus of 0 to 5 wt. carbon black reinforced vinyl ester/glass fiber composites. Flexural strength and modulus increased with the addition of carbon black. Increases in flexural strength were 36\%, 45\%, and $8 \%$ and in flexural modulus were $34 \%, 66 \%$, and $34 \%$ with the addition of carbon black reinforced vinyl ester/glass. The highest increase in flexural strength and modulus was observed for 4 wt.\% carbon blacks and vinyl ester/glass composites.

3.7. Interlaminar Shear Strength (ILSS) of Carbon Black/Vinyl Ester/Glass. Figure 7 shows interlaminar shear strength (ILSS) of 0 to 5 wt.\% carbon black/vinyl ester/glass 


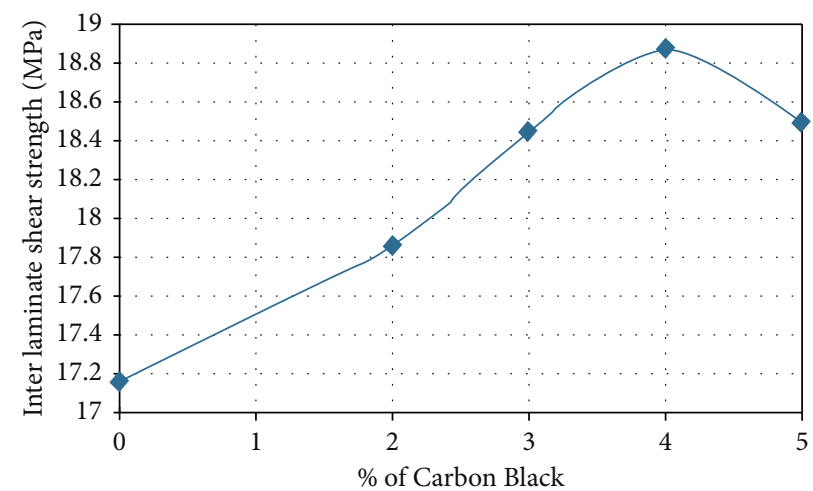

FIGURE 7: Effect of carbon black on interlaminar shear strength of the vinyl ester composites.
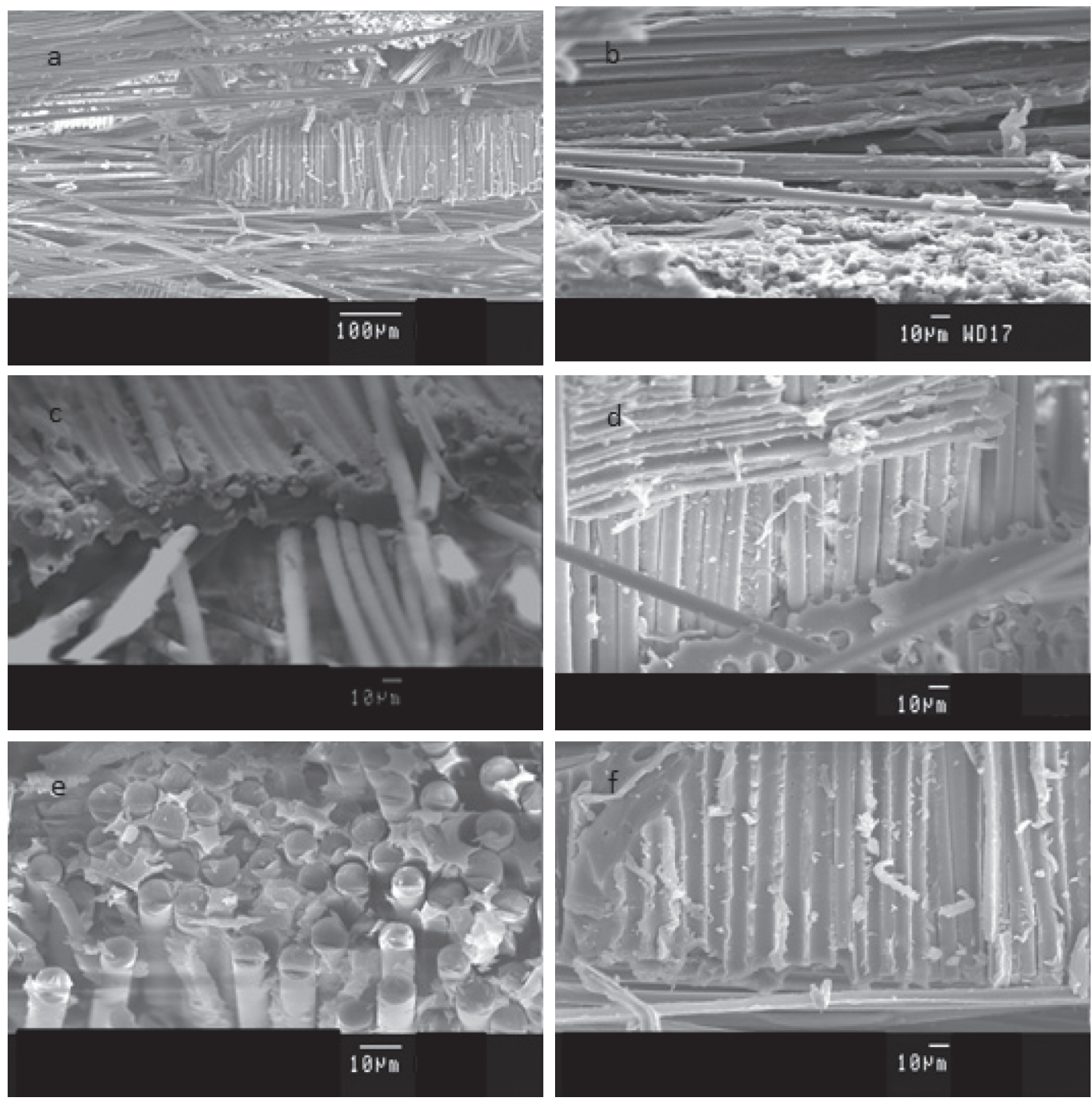

Figure 8: Fracture surface of the (a) glass/vinyl ester composite, (b) 2\% CB reinforced, (c) 3\% CB reinforced, (d) $4 \%$ CB reinforced, and (e) and (f) 5\% CB reinforced glass/vinyl ester composites. 
specimens. ILSS increased with the addition of carbon black. Increases in ILSS were $26 \%, 44 \%$, and $16 \%$ with the addition of carbon black. The highest increment was observed for 4 wt.\% addition of carbon black to vinyl ester.

The present research showed that UTS, Young's modulus, flexural strength, flexural modulus, and ILSS increased with the addition of carbon black to vinyl ester/glass. The highest improvement in mechanical properties was observed for 4 wt.\% of carbon addition to vinyl ester/glass. The improvement in mechanical properties can be attributed to higher basal spacings and the modifier in carbon black, which helped in better exfoliation and stronger interfacial bond between glass fiber and vinyl ester [14-20].

\section{Fracture Studies}

Figure 8 shows SEM of tensile fractured specimen of vinyl ester/glass composites. Fractured fibers in the micrograph are cut straight, and the surfaces are smooth and clean. Clean fiber surface implies failure at the fiber matrix interface, indicating a weak interface bond.

Figure 8(b) shows SEM of tensile fractured specimen of 2 wt.\% carbon black/vinyl ester/glass. The straight cut fibers exhibit better tensile strength, whereas the trace amount of debris attached indicates improper bonding of fibers and resin. Figures $8(\mathrm{c})$ and $8(\mathrm{~d})$ show fractured specimens of 3 and $4 \% \mathrm{CB}$ reinforced vinyl ester/glass composites. Fibers are cut straight and surfaces are adhered with debris of vinyl ester, and the amount of adhered vinyl ester is greater than those of $3 \%$ of CB-based composites. Figure 8(e) shows 5\% $\mathrm{CB}$ reinforced vinyl ester glass composites. Addition of carbon black showed greater amount of vinyl ester adhered to glass fiber surface. This is due to stronger interfacial bond between the $\mathrm{CB}$ and fiber surface.

\section{Conclusion}

Effect of carbon black on the thermal and mechanical properties of vinyl ester and vinyl ester/glass was studied for 0 to 5 wt. $\%$ carbon black/vinyl ester. The following conclusions were drawn based on the present experimental results:

(i) XRD analysis of carbon black/vinyl ester showed exfoliation without any evidence of agglomeration.

(ii) Glass transition temperature of vinyl ester increased with addition of carbon black.

(iii) TGA showed slower rate single stage degradation of the nanocomposites.

(iv) Microhardness of vinyl ester increased addition of carbon black.

(v) Tensile strength, Young's modulus, flexural strength, flexural modulus, and ILSS of vinyl ester/ glass addition carbon black.

(vi) Addition of carbon black improved mechanical properties of vinyl ester/glass which can be explained in complete exfoliation of carbon black in vinyl ester evidenced by XRD studies due to the dispersion of carbon black using ultrasonication and extrusion.

\section{Data Availability}

The data used to support the findings of this study are included within the article.

\section{Conflicts of Interest}

The authors declare that there are no conflicts of interest regarding the publication of this article.

\section{Acknowledgments}

The authors extend their appreciation to the Deanship of Scientific Research at King Khalid University, Saudi Arabia, for funding this work through the Research Group Program under grant no. RGP $1 / 238 / 41$. This study was supported by Taif University Researchers Supporting Project number (TURSP-2020/49), Taif University, Taif, Saudi Arabia. The authors would like to thank Taif University for financial support.

\section{References}

[1] I. Balberg, "A comprehensive picture of the electrical phenomena in carbon black-polymer composites," Carbon, vol. 40, no. 2, pp. 139-143, 2002.

[2] J. P. Adohi, A. Mdarhri, C. Prunier, B. Haidar, and C. Brosseau, "A comparison between physical properties of carbon black-polymer and carbon nanotubes-polymer composites," Journal of Applied Physics, vol. 108, Article ID 074108, 2010.

[3] A. Kausar, "Contemporary applications of carbon black-filled polymer composites: an overview of essential aspects," Journal of Plastic Film and Sheeting, vol. 34, no. 3, pp. 256-299, 2018.

[4] N. Ahmed, A. Kausar, and B. Muhammad, "Shape memory properties of electrically conductive multi-walled carbon nanotube-filled polyurethane/modified polystyrene blends," Journal of Plastic Film and Sheeting, vol. 32, no. 3, pp. 272292, 2016.

[5] B. L. Xing, J. L. Cao, and Y. Wang, "Preparation of lignitebased activated carbon with high specific capacitance for electrochemical capacitors," Funct Mater Lett, vol. 8, Article ID 1550031, 1 page, 2015.

[6] Y. V. Surovikin, A. G. Shaitanov, V. A. Drozdov, I. V. Rezanov, and A. D. Morozov, "Effect of thermal oxidative treatment on the structure and electrical conductivity of nanodispersed carbon black particles," Solid Fuel Chemistry, vol. 48, no. 6, pp. 392-403, 2014.

[7] M.-W. Ho, C.-K. Lam, K.-t. Lau, D. H. L. Ng, D. Hui, and D. Hui, "Mechanical properties of epoxy-based composites using nanoclays," Composite Structures, vol. 75, no. 1-4, pp. 415-421, 2006.

[8] C. Lam and K. Lau, "Theoretical modeling of tribological behavior of nanoclay/epoxy composites," in Proceedings of the 16th International Conference on Composite Materials, Kyoto, Japan, July 2007.

[9] S. Sundaram, R. Nagalingam, and R. Satheesh Raja, "Experimental analysis on tensile properties of FRP with nano clay," International Journal of Advanced Manufacturing Technology, vol. 39, no. 9, pp. 1-5, 2008. 
[10] A. Haque, M. Shamsuzzoha, F. Hussain, and D. Dean, "S2glass/epoxy polymer nanocomposites: manufacturing, structures, thermal and mechanical properties," Journal of Composite Materials, vol. 37, no. 20, pp. 1821-1837, 2003.

[11] X. Kornmann, M. Rees, Y. Thomann, A. Necola, M. Barbezat, and R. Thomann, "Epoxy-layered silicate nanocomposites as matrix in glass fibre-reinforced composites," Composites Science and Technology, vol. 65, no. 14, pp. 2259-2268, 2005.

[12] D. Pantea, H. Darmstadt, S. Kaliaguine, and C. Roy, "Electrical conductivity of conductive carbon blacks: influence of surface chemistry and topology," Applied Surface Science, vol. 217, no. 1-4, pp. 181-193, 2003.

[13] R. Nikhil, S. S. kumar, K. Anupama, and S. Manjunath, "Experimental and numerical investigation of mode II failure behavior evaluation using three point bend, end notched flexure test," MATEC Web of Conferences, vol. 144, Article ID 02009, 2018.

[14] M. Meignanamoorthy, M. Ravichandran, V. Mohanavel et al., "Microstructure, mechanical properties, and corrosion behavior of Boron Carbide Reinforced Aluminum Alloy (Al-Fe$\mathrm{Si}-\mathrm{Zn}-\mathrm{Cu})$ matrix composites produced via powder metallurgy route," Materials, vol. 14, no. 15, Article ID 4315, 2021.

[15] T. H. M. Mysore, A. Y. Patil, G. U. Raju et al., "Investigation of mechanical and physical properties of big sheep horn as an alternative biomaterial for structural applications," Materials, vol. 14, no. 14, Article ID 4039, 2021.

[16] T. Sathish, V. Mohanavel, K. Ansari et al., "Synthesis and characterization of mechanical properties and wire cut edm process parameters analysis in AZ61 magnesium Alloy + B4C + SiC," Materials, vol. 14, no. 13, Article ID 3689, 2021.

[17] B. N. Sharath, C. V. Venkatesh, A. Afzal et al., "Multi ceramic particles inclusion in the aluminium matrix and wear characterization through experimental and response surface-artificial neural networks," Materials, vol. 14, no. 11, Article ID 2895, 2021.

[18] T. Sathish, A. R. R. Kaladgi, V. Mohanavel et al., "Experimental investigation of the friction stir weldability of aa8006 with zirconia particle reinforcement and optimized process parameters," Materials, vol. 14, no. 11, Article ID 2782, 2021.

[19] M. N. Akhtar, M. Khan, S. A. Khan et al., "Determination of non-recrystallization temperature for niobium microalloyed steel," Materials, vol. 14, no. 10, Article ID 2639, 2021.

[20] S. Nagaraja, K. U. Nagegowda, A. Kumar V et al., "Influence of the fly ash material inoculants on the tensile and impact characteristics of the Aluminum AA 5083/7.5SiC composites," Materials, vol. 14, no. 9, Article ID 2452, 2021. 